\title{
Alveolar ridge preservation following extraction of multiple anterior teeth with and without adjunctive enamel matrix derivative: $A$ case report
}

\author{
Bo-Ram Nam ${ }^{1,2 \dagger}$, Yeon-Tae Kim ${ }^{1,2 \dagger}$, Seong-Nyum Jeong ${ }^{1,2}$, Jae-Hong Lee ${ }^{1,2 \star}$ \\ ${ }^{1}$ Department of Periodontology, Wonkwang University Daejeon Dental Hospital, Wonkwang University College of Dentistry, Daejeon, Korea \\ ${ }^{2}$ Institute of Wonkwang Dental Research, Wonkwang University College of Dentistry, Iksan, Korea
}

The objective of this study was to evaluate the dynamics of bone dimensional change in extraction sockets with alveolar ridge preservation (ARP) procedure with or without enamel matrix derivatives (EMD). ARP was performed in two patients after extraction of maxillary central incisors and lateral incisors. Deproteinized bovine bone mineral with $10 \%$ collagen covered by two layers of a native bilayer collagen membrane with adjunctive use of EMD (patient 1) and without EMD (patient 2). Radiological and clinical findings: adjunctive use of EMD in ARP showed similar horizontal and vertical bone dimensional changes and soft tissue healing outcomes (spontaneous bleeding, persistent swelling, and ulceration) but the duration of postoperative pain and swelling was reduced.

Key Words: Bone regeneration, Enamel matrix derivatives, Wound healing

(c) This is an open-access article distributed under the terms of the Creative Commons Attribution Non-Commercial License (http://creativecommons.org/licenses/by-nc/4.0) which permits unrestricted noncommercial use, distribution, and reproduction in any medium, provided the original work is properly cited.

\section{서 론}

치조골의 모양과 형태는 치아의 형태, 맹출 및 장축의 방향에 따라 결정된다. 외상, 치주질환, 치아우식증 등의 다양한 원인으 로 초래된 치아의 상실은 치아 주위 경조직 및 연조직의 필연적 변화를 초래한다. 이러한 발치와의 생리학적 변화 과정은 발치 와의 크기, 점막의 두께, 대사 인자, 기능적 부하 등 다양한 변수 에 의해 영향을 받는다[1]. 선행 연구들에서 발치 6개월 뒤 수평 골소실은 29\%- $63 \%$, 수직 골소실은 $11 \%-22 \%$ 정도 발생하며, 평균적으로 $40 \%-60 \%$ 의 골소실이 발생하는 것으로 보고되었 다. 또한, 발치와의 협측골은 많은 양의 다발골로 이루어져 있기 때문에, 발치 후 기능을 상실하여 설측골에 비해 더 많은 흡수를 보인다. 이러한 치조골의 폭과 높이의 감소는 이후의 임플란트
식립을 어렵게 하거나 불가능하게 하며, 이상적인 심미적 보철 물과 임플란트의 기능에 부정적 결과를 초래한다[2-4].

치조제 보존술(alveolar ridge preservation, ARP)은 본래의 치조정 형태를 최대한 보존하고 치조골의 흡수를 지연시키기 위하여 발치 즉시 이식재 및 차폐막 또는 연조직 피개 등을 동반 하는 술식이다[5,6]. ARP에는 다양한 재료들이 사용되고 있으 며, 이식재로는 자가골, 동종골, 이종골, 합성골 등이 이용되고 있다. 차폐막으로는 비흡수성 polytetrafluoroethylene, 흡수성 비가교성 및 가교성 콜라겐 등이 유용하게 사용되고 있다[7,8].

최근에는 platelet-rich plasma, platelet-rich fibrin, bone morphogenetic protein, enamel matrix derivate (EMD) 그리 고 cell therapy와 같이 다양한 재료들과 술식들이 발치와의 보 존 및 증대를 향상시키기 위하여 꾸준히 연구되고 있다[9]. 그

Received April 8, 2019; Revised April 27, 2019; Accepted May 7, 2019

Corresponding author: Jae-Hong Lee, Department of Periodontology, Wonkwang University Daejeon Dental Hospital, Wonkwang University College of Dentistry, 77 Dunsan-ro, Seo-gu, Daejeon 35233, Korea.

Tel: +82-42-366-1114, Fax: +82-42-366-1115, E-mail: ljaehong@gmail.com

${ }^{\dagger}$ These authors contributed equally to this work.

Copyright $\odot$ 2019, Oral Biology Research Institute 
중 EMD는 치배로부터 유래된 amelogenin을 비롯한 다양한 단 백질로 구성되며, 여러 임상 연구에서 치주낭 감소, 임상 부착 수준의 증가 및 골 내 결손 해소 등에 효과가 있음이 보고되었다 [10,11]. 따라서, 골재생 및 연조직 치유 촉진을 목적으로 비외 과적 치주치료뿐만 아니라 재생형 치주치료, 연조직 증강술 등 의 다양한 술식에 유용하게 사용되고 있지만, ARP에 추가적인 사용으로 인한 이점에 대한 임상 연구는 부족한 실정이다. 이에 본 연구에서는 발치 후 $\mathrm{ARP}$ 시행 시 콜라겐이 혼합된 탈단백 우 골 이식재 및 흡수성 콜라겐 차폐막 단독 사용과 $\mathrm{EMD}$ 를 추가적 으로 적용한 경우를 임상적, 방사선학적으로 평가하고자 한다.

\section{증례보고}

\section{술식}

두 환자의 발치 및 $\mathrm{ARP}$ 모두 한 명의 치주 전문의에 의해 서 시행되었다. 각 치아는 국소마취( $2 \%$ lidocaine $\mathrm{HCl}$ with 1:100,000 epinephrine; Yuhan, Seoul, Korea)하에 페리오톰 과 발치기자(Hu-Friedy, Chicago, IL, USA)를 이용하여 조심스 럽게 발거되었다. 수술도와 골막기자를 이용한 판막 거상은 시 행하지 않았으며, 수술용 큐렛(standard and mini Gracey curettes; Hu-Friedy)을 통해 발치와 내의 육아조직 및 염증조직 을 제거하였다.
환자1: 상악 좌측 중절치 및 측절치를 발치 후, 발치와에 탈 단백 우골과 $10 \%$ 콜라겐이 혼합된 이식재(deproteinized bovine bone-Collagen [DBBM-C], Geistlich Bio-Oss Collagen; Geistlich Pharma AG, Wolhusen, Switzerland)와 EMD (Straumann Emdogain; Straumann, Basel, Switzerland) 를 동시에 적용하였다. 그 후 비가교화 흡수성 콜라겐 차폐막 (non-cross-linked resorbable collagen membrane [NCLM], Geistlich Bio-Gide; Geistlich Pharma AG)을 두 겹으로 적용 하였다. NCLM은 결손부 변연으로부터 2-3 mm 연장하여 발치 와를 피개할 수 있도록 한 후, 비흡수성 polytetrafluoroethylene monofilament (Biotex; Purgo, Seongnam, Korea)를 이 용하여 수평누상봉합과 단속봉합을 시행하였다. 6 개월 뒤, 임플 란트 식립을 진행하였다(Fig. 1).

환자2: 상악 우측 중절치 및 측절치를 발치한 후, 환자 1과 동 일한 처치를 시행하였으며, 발치와에 EMD 적용 없이 DBBM-C 만을 적용하고 동일한 NCLM을 두 겹 적용 후, 수평누상봉합과 단속봉합을 시행하였다(Fig. 2).

두 환자 모두 수술 후 항생제(아목시실린 $500 \mathrm{mg}, 5$ 일[1일 3회]), 진통제(이부프로펜 $200 \mathrm{mg}$, 5일[1일 3회]), 구강청결제 $(0.12 \%$ 클로르헥시딘, 10 일[1일 2회, 1분간])를 처방하였다. 봉 합사는 수술 후 2주 뒤에 제거하였다. 발치 직후(baseline), 3 개월, 6개월 뒤 콘빔 전산화 단층촬영(cone-beam computed tomography)을 시행하였으며, 술 전 및 ARP 직후, 3 개월, 6 개
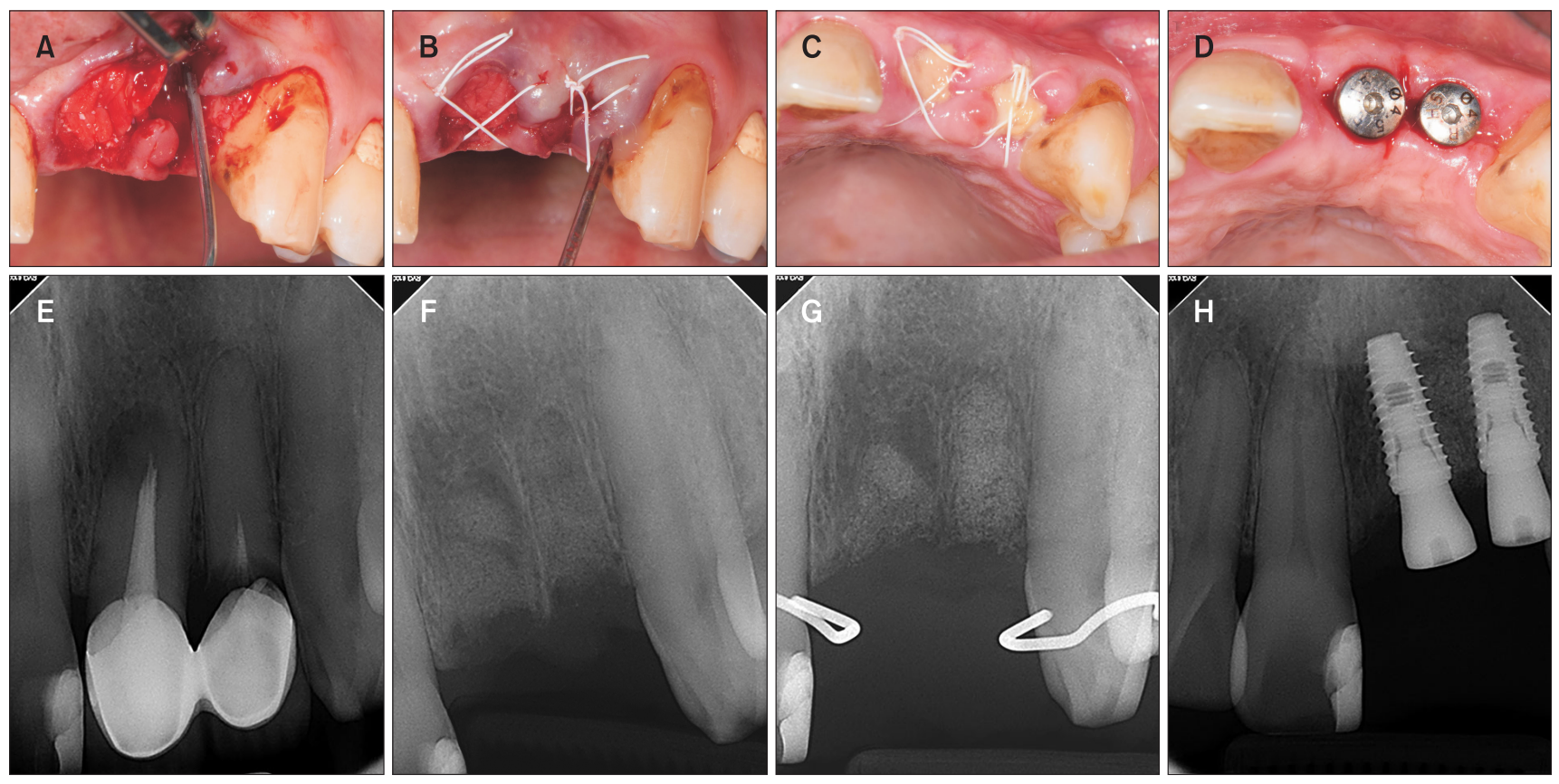

Fig. 1. Representative clinical photos and radiographic images after tooth extraction and alveolar ridge preservation with adjunctive use of enamel matrix derivate at baseline (A, B, E, and F), 3 months (C and G), 6 months (D and $H$ ), respectively. 

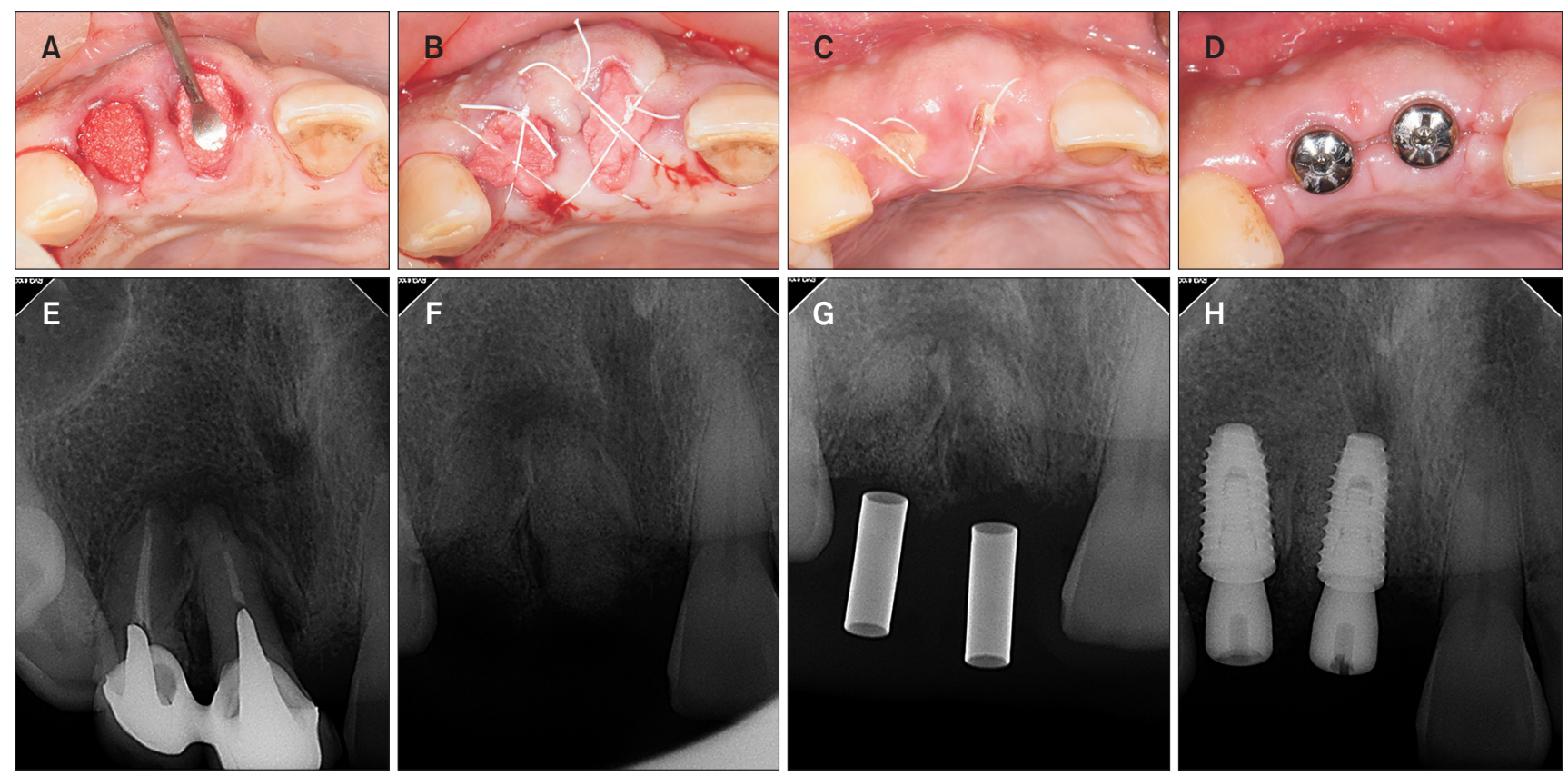

Fig. 2. Representative clinical photos and radiographic images after tooth extraction and alveolar ridge preservation without adjunctive use of enamel matrix derivate at baseline (A, B, E, and F), 3 months (C and $G), 6$ months (D and $H$ ), respectively.

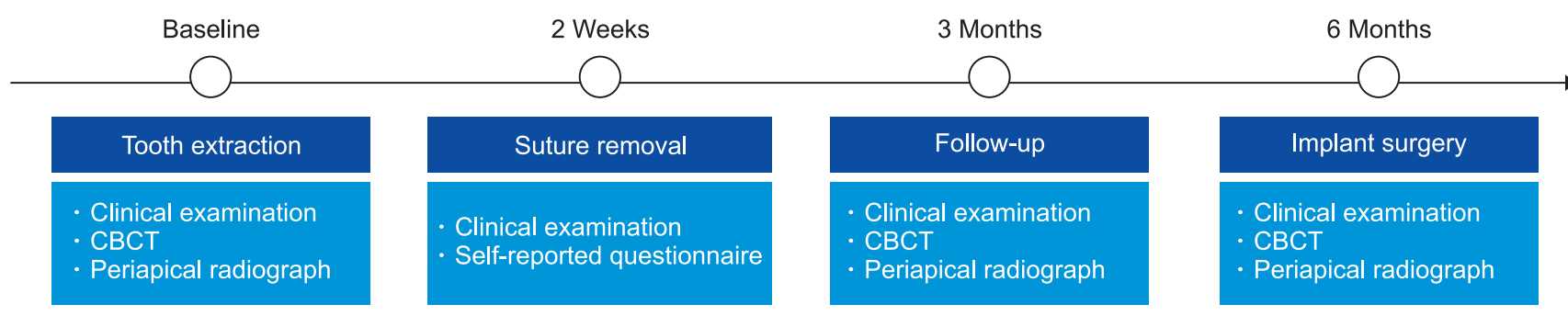

Fig. 3. Schematic presentation of the study protocol. CBCT, cone-beam computed tomography.

월 뒤 치근단 방사선 사진도 촬영하였다(Fig. 3).

\section{방사선학적 소견}

치조정에 수직 방향으로 평행한 세 가지 수직 기준선(협측, 중 앙, 구개 측)을 정하였다. 수평 기준선의 경우, 치조정으로부터 각각 $1 \mathrm{~mm}, 3 \mathrm{~mm}, 5 \mathrm{~mm}$ 위치에 수직 기준선의 직각으로 설정 하였다. 이러한 기준선들은 수직적 변화량(vertical change of the buccal alveolar crest [VHB], vertical change of the midalveolar crest [VHM], vertical change of the lingual alveolar crest [VHP]), 수평적 변화량(horizontal width in the $1 \mathrm{~mm}$ apically below the ridge crest [HW1], HW3, HW5)을 측정하 기 위해 사용되었다.

한 환자당 상악 전치부 두 치아에서 $\mathrm{ARP}$ 를 진행하였으며, 모
든 방사선학적 측정값은 평균값을 표기하였다. 두 환자의 수평 적, 수직적 골 변화를 baseline을 시점으로 비교하였을 때 3개월 후 두 환자 모두 비슷한 양의 골 소실을 나타내었으며 수평 골소 실의 경우 치조정에 가까울수록 그 양이 더 많았다(HW1 [-1.3 $\mathrm{mm}$ vs. $-1.2 \mathrm{~mm}]>\mathrm{HW} 3[-0.8 \mathrm{~mm}$ vs. $-0.7 \mathrm{~mm}]>\mathrm{HW} 5[-0.4$ $\mathrm{mm}$ vs. $-0.4 \mathrm{~mm}]$ ). 수직적으로는 협설 방향으로 약간 더 많 은 골소실 양상을 보였다(VHB [-1.1 mm vs. $-1.2 \mathrm{~mm}]$, VHM [-1.0 mm vs. $-1.1 \mathrm{~mm}]$, VHP [-1.2 mm vs. $-1.3 \mathrm{~mm}]$ ). 이는 6개월 시점에서도 같은 양상을 보였으며 그 양은 미미하지만 약 간 더 증가하거나 비슷한 수준으로 관찰되었다(Table 1).

\section{임상적 소견}

수술 후 2주 시점에서 두 환자 모두 잔존하는 부종이나 궤양 
Table 1. Horizontal and vertical ridge changes from baseline to 3 and 6 months follow-up

\begin{tabular}{|c|c|c|c|c|}
\hline & \multicolumn{2}{|c|}{3 Months } & \multicolumn{2}{|c|}{6 Months } \\
\hline & Patient 1 & Patient 2 & Patient 1 & Patient 2 \\
\hline \multicolumn{5}{|c|}{ Horizontal changes $(\mathrm{mm})$} \\
\hline HW1 & -1.3 & -1.2 & -1.4 & -1.4 \\
\hline HW3 & -0.8 & -0.7 & -0.9 & -0.8 \\
\hline HW5 & -0.4 & -0.4 & -0.5 & -0.5 \\
\hline \multicolumn{5}{|c|}{ Vertical changes (mm) } \\
\hline VHB & -1.1 & -1.2 & -1.2 & -1.3 \\
\hline VHM & -1.0 & -1.1 & -1.1 & -1.1 \\
\hline VHP & -1.2 & -1.3 & -1.2 & -1.3 \\
\hline
\end{tabular}

Values are presented as mean.

HW1/3/5, horizontal width in the 1-, 3-, and 5-mm apically below the ridge crest; VHB, vertical change of the buccal alveolar crest; VHM, vertical change of the mid-alveolar crest; VHP, vertical change of the lingual alveolar crest.

Table 2. Early wound healing after 2 weeks follow-up

\begin{tabular}{lcc}
\hline & Patient $\mathbf{1}$ & Patient $\mathbf{2}$ \\
\hline Spontaneous bleeding & No & Yes \\
Persistent swelling & No & No \\
Ulceration & No & No \\
\hline
\end{tabular}

등은 관찰되지 않았으나 $\mathrm{EMD}$ 를 적용하지 않은 환자에서만 자 발적 출혈 양상이 관찰되었다(Table 2).

\section{술 후 불편감}

환자들은 각각 술 후 불편감에 대한 설문지를 작성하였으며 상처 치유 양상(술 후 부종, 자발적 출혈 양상, 궤양 여부)에 대 해 봉합사를 제거(ARP 후 2주)할 때 평가되었다. 주관적인 통증 과 부종의 정도는 통증평가지수(visual analog scale, VAS; 범위 0-10)를 사용하여 평가하였고 통증과 부종의 지속기간 또한 조 사하였다. 술 후 불편감에 대한 설문 조사에서 통증 강도와 부종 정도는 두 환자가 비슷하게 응답하였으나(VAS scale 3-4), 통증 과 부종의 기간에 대해서는 $\mathrm{EMD}$ 를 사용하지 않은 환자가 각각 5 일, 7일로 $\mathrm{EMD}$ 를 사용한 환자가 답변한 3일, 5일보다 2일 정 도 더 오래 지속되었다고 응답하였다(Table 3).

\section{고 찰}

발치 후 치조골의 흡수를 완벽하게 막을 수는 없으나, ARP를 통하여 치조골의 폭과 높이의 감소를 효과적으로 제한할 수 있 음이 여러 선행 연구들을 통하여 일관되게 보고되고 있다[1216]. Barone 등[14]의 연구에서는 이종골과 콜라겐 흡수성 차폐 막을 사용하여 $\mathrm{ARP}$ 를 시행하였을 때, 그렇지 않은 경우에 비하
Table 3. Comparison of early postoperative discomfort

\begin{tabular}{lcc}
\hline & Patient 1 & Patient 2 \\
\hline Severity of subjective pain (VAS scale) & 3 & 4 \\
Severity of subjective swelling (VAS scale) & 4 & 4 \\
Durations of subjective pain (d) & 3 & 5 \\
Durations of subjective swelling (d) & 5 & 7 \\
\hline
\end{tabular}

VAS, visual analog scale.

여 55\% 가량 협설측 폭경의 흡수가 감소하였으며, $90 \%$ 가량 수 직골 흡수가 예방됨을 보고하였다. Cardaropoli 등[15] 또한 발 치 4 개월 후 비처치군이 $4.48 \pm 0.65 \mathrm{~mm}$ 의 협설폭 감소를 보인 것에 비해 $\mathrm{ARP}$ 처치군에서는 $1.04 \pm 1.08 \mathrm{~mm}$ 의 감소를 보였으 며, mid-buccal 높이는 비처치군에서 $1.54 \pm 0.33 \mathrm{~mm}$, ARP 처 치군은 $0.46 \pm 0.46 \mathrm{~mm}$ 의 감소를 보고하여 $\mathrm{ARP}$ 의 유용성을 보 고하였다.

$\mathrm{EMD}$ 는 골모세포의 증식, 이동, 분화를 촉진하고 생존 능력을 향상시켜 골수 및 골 형성 잠재력을 향상시키는 것으로 보고되 었다[17]. 또한, 실험실 연구에서 골 재형성에 영향을 주는 주요 한 전사인자, 시토카인, 성장인자들의 발현 및 조절에 영향을 미 치는 것을 확인하였다[11,18]. 여러 선행 연구들에서 $\mathrm{EMD}$ 가 치 주치료의 결과를 향상시킨다는 강력한 증거를 제공하지만, 토 끼 두개부 결손, 임플란트 주위 결손 등을 대상으로 이루어진 다 양한 이식재료들과의 조합 연구에서 신생골의 형성에 이점이 있는지를 밝히는 데는 실패하였다[19-21].

이번 연구에서도 $\mathrm{ARP}$ 에 추가적인 $\mathrm{EMD}$ 의 적용이 골재생을 촉진할 것으로 기대하였으나 그렇지 않은 경우와 방사선학적으 로 비교하였을 때, 수평 및 수직골 흡수량에 차이를 보이지 않았 다. 이는 $\mathrm{EMD}$ 의 적용이 $\mathrm{ARP}$ 시행 후 점진적으로 발생하는 골 흡수, 특히 협측골의 흡수를 보상할 정도로 골재생 능력이 크지 않음을 의미할 수 있다. 이러한 방사선학적 결과는 과거 선행 연 
구들과 유사한 결과이다[22,23].

$\mathrm{EMD}$ 는 초기 각화 치은의 증식을 두 배 정도 빠르게 진행시 키고, 초기 연조직의 치유에 도움을 준다[24]. Maymon-Gil 등 [25]의 연구에서 EMD의 사용이 혈관 수와 콜라겐 함량을 유 의하게 증가시켰으며, transforming growth factor (TGF)- $\beta 1$ 과 TGF- $\beta 3$, vascular endothelial growth factor, interleukin-1 $\beta$, matrix metalloproteinase- 1 및 fibronectin의 발현을 $20 \%-40 \%$ 향상시킴을 보고하였다. Wennström과 Lindhe [26] 는 $\mathrm{EMD}$ 의 적용이 비수술적, 수술적 치주 처치에 있어 치조-치 은 부위의 초기 치유를 향상시키며 환자의 술 후 불편감을 감소 시킬 수 있음을 보고하였다. Tonetti 등[27]도 치주 수술에 있어 $\mathrm{EMD}$ 의 추가적인 사용이 초기 치유에 도움이 될 수 있음을 보고 하였다.

이번 연구에서 $\mathrm{ARP}$ 에 $\mathrm{EMD}$ 를 추가 적용한 경우, 환자가 느끼 는 통증 및 부종의 정도와 기간이 감소함을 확인할 수 있었으며, 이는 치주 수술 진행 시 $\mathrm{EMD}$ 를 추가 적용한 경우, 환자의 주관 적 통증 및 부종의 정도가 통계적으로 유의하게 감소하였다는 과거의 연구와 일치하는 결과이다[28]. 또한, 선행연구에서도 골재생 능력은 $\mathrm{EMD}$ 를 사용한 군과 그렇지 않은 군 사이에 통계 적으로 차이가 없음을 고려할 때, 치주 및 임플란트 영역의 수술 을 진행할 때 $\mathrm{EMD}$ 의 사용이 골재생 효과보다는 초기 연조직 치 유 효과에 도움을 줄 수 있을 것으로 보인다.

이번 연구에서는 두 명으로 한정된 증례보고로 매우 제한적 인 임상 및 방사선학적 결과를 확인할 수 있었다. 조직학적 계 측이 이루어지지 않아 $\mathrm{EMD}$ 의 추가적인 적용이 발치와에서 신 생골의 형성에 효과적인지는 확인할 수 없다는 한계점이 존재 한다. 또한, 고가의 재료를 추가 사용하는 것이 ARP 후 동통이 나 부종 경감에 도움이 되는지는 신중하게 고려해 보아야 할 필 요가 있다. 차후 다양한 골이식재 및 술식과의 조합을 통하여 골 재생 효과의 평가가 필요할 것으로 보이며, 특히, ARP에서 추가 적으로 $\mathrm{EMD}$ 가 사용된 임상 연구는 부족한 만큼 분할구강모형 (split mouth design)이나 무작위 대조군 임상 연구를 통한 임 상적, 방사선학적, 조직학적 연구가 필요할 것으로 고려된다.

\section{ACKNOWLEDGEMENTS}

This research was supported by Wonkwang University in 2019.

\section{CONFLICTS OF INTEREST}

The authors declare that they have no competing interests.

\section{ORCID}

\author{
Bo-Ram Nam \\ https://orcid.org/0000-0001-5708-9956 \\ Yeon-Tae Kim \\ https://orcid.org/0000-0001-7209-3208 \\ Seong-Nyum Jeong \\ https://orcid.org/0000-0003-4890-989X \\ Jae-Hong Lee \\ https://orcid.org/0000-0002-2375-0141
}

\section{REFERENCES}

1. Maiorana C, Poli PP, Deflorian M, Testori T, Mandelli F, Nagursky H, Vinci R. Alveolar socket preservation with demineralised bovine bone mineral and a collagen matrix. J Periodontal Implant Sci 2017;47:194-210. doi: 10.5051/ jpis.2017.47.4.194.

2. Araújo MG, Lindhe J. Dimensional ridge alterations following tooth extraction. An experimental study in the dog. J Clin Periodontol 2005;32:212-218. doi: 10.1111/j.1600051X.2005.00642.x.

3. Fickl S, Zuhr O, Wachtel H, Bolz W, Huerzeler MB. Hard tissue alterations after socket preservation: an experimental study in the beagle dog. Clin Oral Implants Res 2008;19:1111-1118. doi: 10.1111/j.1600-0501.2008.01575. $\mathrm{x}$.

4. Wang HL, Tsao YP. Mineralized bone allograft-plug socket augmentation: rationale and technique. Implant Dent 2007;16:33-41. doi: 10.1097/ID.0b013e318031ece6.

5. Becker W. Treatment of small defects adjacent to oral implants with various biomaterials. Periodontol 2000 2003;33:26-35. doi: 10.1046/j.0906-6713.2003.03303.x.

6. Froum S, Cho SC, Rosenberg E, Rohrer M, Tarnow D. Histological comparison of healing extraction sockets implanted with bioactive glass or demineralized freeze-dried bone allograft: a pilot study. J Periodontol 2002;73:94-102. doi: 10.1902/jop.2002.73.1.94.

7. Araújo M, Linder E, Lindhe J. Effect of a xenograft on early bone formation in extraction sockets: an experimental study in dog. Clin Oral Implants Res 2009;20:1-6. doi: 10.1111/j.1600-0501.2008.01606.x.

8. Artzi Z, Tal H, Dayan D. Porous bovine bone mineral in healing of human extraction sockets. Part 1: histomorphometric evaluations at 9 months. J Periodontol 2000;71: 1015-1023. doi: 10.1902/jop.2000.71.6.1015.

9. Jamjoom A, Cohen RE. Grafts for ridge preservation. J Funct Biomater 2015;6:833-848. doi: 10.3390/jfb6030833.

10. Froum SJ, Weinberg MA, Rosenberg E, Tarnow D. A comparative study utilizing open flap debridement with and without enamel matrix derivative in the treatment of peri- 
odontal intrabony defects: a 12-month re-entry study. J Periodontol 2001;72:25-34. doi: 10.1902/jop.2001.72.1.25.

11. Bosshardt DD. Biological mediators and periodontal regeneration: a review of enamel matrix proteins at the cellular and molecular levels. J Clin Periodontol 2008;35(8 Suppl):87-105. doi: 10.1111/j.1600-051X.2008.01264.x.

12. Avila-Ortiz G, Elangovan S, Kramer KW, Blanchette D, Dawson DV. Effect of alveolar ridge preservation after tooth extraction: a systematic review and meta-analysis. J Dent Res 2014;93:950-958. doi: 10.1177/0022034514541127.

13. Horowitz R, Holtzclaw D, Rosen PS. A review on alveolar ridge preservation following tooth extraction. J Evid Based Dent Pract 2012;12(3 Suppl):149-160. doi: 10.1016/ S1532-3382(12)70029-5.

14. Barone A, Aldini NN, Fini M, Giardino R, Calvo Guirado JL, Covani U. Xenograft versus extraction alone for ridge preservation after tooth removal: a clinical and histomorphometric study. J Periodontol 2008;79:1370-1377. doi: 10.1902/jop.2008.070628.

15. Cardaropoli D, Tamagnone L, Roffredo A, Gaveglio L, Cardaropoli G. Socket preservation using bovine bone mineral and collagen membrane: a randomized controlled clinical trial with histologic analysis. Int J Periodontics Restorative Dent 2012;32:421-430. doi: 10.11607/prd.00.1078.

16. Festa VM, Addabbo F, Laino L, Femiano F, Rullo R. Porcinederived xenograft combined with a soft cortical membrane versus extraction alone for implant site development: a clinical study in humans. Clin Implant Dent Relat Res 2013;15:707-713. doi: 10.1111/j.1708-8208.2011.00398.x.

17. Birang R, Abouei MS, Razavi SM, Zia P, Soolari A. The effect of an enamel matrix derivative (Emdogain) combined with bone ceramic on bone formation in mandibular defects: a histomorphometric and immunohistochemical study in the canine. ScientificWorldJournal 2012;2012:196791. doi: 10.1100/2012/196791.

18. Grandin HM, Gemperli AC, Dard M. Enamel matrix derivative: a review of cellular effects in vitro and a model of molecular arrangement and functioning. Tissue Eng Part B Rev 2012;18:181-202. doi: 10.1089/ten.TEB.2011.0365.

19. Intini G, Andreana S, Buhite RJ, Bobek LA. A comparative analysis of bone formation induced by human demineralized freeze-dried bone and enamel matrix derivative in rat calvaria critical-size bone defects. J Periodontol 2008;79:1217-1224. doi: 10.1902/jop.2008.070435.

20. Donos N, Lang NP, Karoussis IK, Bosshardt D, Tonetti M, Kostopoulos L. Effect of GBR in combination with de- proteinized bovine bone mineral and/or enamel matrix proteins on the healing of critical-size defects. Clin Oral Implants Res 2004;15:101-111. doi: 10.1111/j.1600-0501. 2004.00986.x.

21. Casati MZ, Sallum EA, Nociti FH Jr, Caffesse RG, Sallum AW. Enamel matrix derivative and bone healing after guided bone regeneration in dehiscence-type defects around implants. A histomorphometric study in dogs. J Periodontol 2002;73:789-796. doi: 10.1902/jop.2002.73.7.789.

22. Nevins ML, Camelo M, Schupbach P, Nevins M, Kim SW, Kim DM. Human buccal plate extraction socket regeneration with recombinant human platelet-derived growth factor BB or enamel matrix derivative. Int J Periodontics Restorative Dent 2011;31:481-492. doi: 10.11607/ prd.00.1009.

23. Alkan EA, Parlar A, Yildirim B, Sengüven B. Histological comparison of healing following tooth extraction with ridge preservation using enamel matrix derivatives versus Bio-Oss Collagen: a pilot study. Int J Oral Maxillofac Surg 2013;42:1522-1528. doi: 10.1016/j.ijom.2013.06.002.

24. Al-Hezaimi K, Al-Fahad H, O'Neill R, Shuman L, Griffin $\mathrm{T}$. The effect of enamel matrix protein on gingival tissue thickness in vivo. Odontology 2012;100:61-66. doi: 10.1007/s10266-011-0022-5.

25. Maymon-Gil T, Weinberg E, Nemcovsky C, Weinreb M. Enamel matrix derivative promotes healing of a surgical wound in the rat oral mucosa. J Periodontol 2016;87:601609. doi: 10.1902/jop.2016.150567.

26. Wennström JL, Lindhe J. Some effects of enamel matrix proteins on wound healing in the dento-gingival region. J Clin Periodontol 2002;29:9-14. doi: 10.1034/j.1600-051x. 2002.290102.x.

27. Tonetti MS, Lang NP, Cortellini P, Suvan JE, Adriaens P, Dubravec D, Fonzar A, Fourmousis I, Mayfield L, Rossi R, Silvestri M, Tiedemann C, Topoll H, Vangsted T, Wallkamm B. Enamel matrix proteins in the regenerative therapy of deep intrabony defects. J Clin Periodontol 2002;29:317325. doi: 10.1034/j.1600-051X.2002.290407.x.

28. Tonetti MS, Fourmousis I, Suvan J, Cortellini P, Brägger U, Lang NP; European Research Group on Periodontology (ERGOPERIO). Healing, post-operative morbidity and patient perception of outcomes following regenerative therapy of deep intrabony defects. J Clin Periodontol 2004;31:1092-1098. doi: 10.1111/j.1600-051X.2004. 00615.x. 